\title{
Prevalence of and risk factors for feline hyperthyroidism in Hong Kong
}

\author{
Cornelia S. De Wet BVSc (Hons) ${ }^{1}$, Carmel T. Mooney MVB, MPhil, PhD, DECVIM- \\ $\mathrm{CA}^{3}$, Peter N. Thompson BVSc, MMedVet (Med), Phd ${ }^{2}$ and Johan P. Schoeman BVSC, \\ MMedVet, DSAM, DECVIM-CA ${ }^{1}$
}

${ }^{1}$ Department of Companion Animal Clinical Studies, Section of Small Animal Medicine, Faculty of Veterinary Science, University of Pretoria, South Africa

${ }^{2}$ Department of Production Animal Studies, Section of Epidemiology, Faculty of Veterinary Science, University of Pretoria, South Africa

${ }^{3}$ University Veterinary Hospital, University College Dublin, Ireland

\begin{abstract}
A study was conducted to determine the prevalence of and potential risk factors for feline hyperthyroidism in Hong Kong. Serum total thyroxine $\left(T_{4}\right)$ was measured in 305 cats aged 10 years and older that presented at various veterinary clinics in Hong Kong. The prevalence of hyperthyroidism $\left(T_{4}>50 \mathrm{nmol} / \mathrm{l}\right)$ within this population was $3.93 \%$ and there was no significant difference in prevalence between healthy (3.16\%) and sick (4.37\%) cats. Older cats (>15 years) were more likely to be affected and domestic shorthair cats were less likely to be diagnosed with hyperthyroidism than the other breeds combined. No specific association between the development of feline hyperthyroidism and food type was observed. The prevalence of feline hyperthyroidism in Hong Kong was less than that reported for most other parts of the world, despite the presence of previously identified risk factors.
\end{abstract}

\section{Introduction}

Feline hyperthyroidism is a multi-systemic disorder resulting from excessive circulating concentrations of 1-tri-iodothyronine $\left(\mathrm{T}_{3}\right)$ and, or, 1-thyroxine $\left(\mathrm{T}_{4}\right){ }^{1,2,3}$ and 4 The illness occurs in middle to old age cats, with a reported range of 4-22 years (median age approximately 13 years). ${ }^{4}$ Only $5 \%$ of hyperthyroid cats are younger than 10 years of age at the time of diagnosis. ${ }^{4}$ The disease was first reported in cats in 1979 and has since been recognised with increasing frequency. $5,6,7,8,9,10$ and 11 It is now accepted as the most common endocrine 
disorder in cats and the most important cause of morbidity in middle-aged cats in the United States ${ }^{9,10}$ and 12 and the United Kingdom. ${ }^{3}$ The disease is also commonly seen in Australia, Canada, Europe, Japan and New Zealand. 12, 13, 14, 15, 16,17 and 18

Not much is known about the worldwide distribution of feline hyperthyroidism and there are very few published incidence rates or prevalence estimates. ${ }^{9}$ A report on the hospital prevalence in veterinary hospitals in North America suggested that there was a marked increase between 1979 and $1985 .{ }^{8}$ The average prevalence in 1979 was $0.3 \%$ and in 1985 that number had increased to $4.5 \%$. Edinboro et $\mathrm{al}^{19}$ reported that age-adjusted hospital prevalence in North America increased from $0.1 \%$ in $1978-1982$ to $2 \%$ in the period of $1993-1997$. An increase in the hospital prevalence was also reported in Germany where the number of affected cats increased from $0.2 \%$ in $1987-1994$ to $2.6 \%$ in $1998 .{ }^{20}$ Miyamoto et al ${ }^{16}$ reported a prevalence of $8.9 \%$ in cats 9 years and older that were brought to hospitals in two areas in Japan whilst Sassnau ${ }^{18}$ reported a prevalence of $11.4 \%$ among cats 8 years and older in an urban population in Germany. Wakeling et $\mathrm{al}^{21}$ reported a yearly incidence of $11.92 \%$ for cats older than 9 years of age in a first opinion hospital in the United Kingdom. So far the cause of the worldwide occurrence as well as the increased incidence has eluded scientists and it has been postulated that immunological, infectious, nutritional (eg, iodine), environmental (eg, toxins or goitrogens), or genetic factors may play a role in the development of the condition. ${ }^{9}$ $12,13,22$ and 23

The first published case-control study of cats with hyperthyroidism found associations between hyperthyroidism and consumption of canned food in the 5 years prior to diagnosis, partial or complete indoor housing, non-Siamese breed, and regular exposure to fertilizers, herbicides and pesticides used on the lawn and flea control products. ${ }^{8}$ A subsequent study found that consumption of canned commercial cat food and use of cat litter were significantly associated with greater risk of hyperthyroidism. ${ }^{24}$ Use of topical ectoparasite preparations was less strongly associated with increased risk of developing hyperthyroidism. Both Siamese and Himalayan cats had significantly lower risk compared to other cat breeds. A further study found that increasing age and preference for fish or liver and giblets flavours of commercial canned food in the present diet were associated with greater risk of hyperthyroidism. ${ }^{25}$ A more recent study concluded that the increase of feline hyperthyroidism was not solely the result of ageing of the cat population and a significant association was found between hyperthyroidism and consumption of canned food, particularly pop-top cans. ${ }^{19}$ In that study the risk for hyperthyroidism was found to be greater for female than for male cats. Olczak et al ${ }^{17}$ also found that female cats, cats eating canned food and cats sleeping on 
the floor, were at greater risk of developing hyperthyroidism. In addition, they found that purebred cats were at much lower risk of being diagnosed with hyperthyroidism than domestic short- and longhaired cats. In a small survey in 2006, Sassnau found that the prevalence of feline hyperthyroidism increased with age. Significantly more male than female cats were affected in that study.

All these studies suggest that diet may play a role in the pathogenesis of feline hyperthyroidism and the iodine content of different cat foods has been investigated. ${ }^{26}$ and 27 The concentration of iodine varies widely in commercial cat foods in the United States and New Zealand, with some foods containing very small amounts and others have amounts dramatically exceeding current recommendations for cats. This variation has fuelled speculation that cats eating diets varying in iodine content over time may be more likely to develop hyperthyroidism.

Further research into the worldwide prevalence as well as presence of possible causative factors would help to shed light on the cause and pathogenesis of this disease and lead to preventative measures. ${ }^{9}$ As far as the authors are aware, no prevalence studies have been completed in Hong Kong, a geographic area in which hyperthyroidism in cats is thought to be rare. The main aims of this study were to determine the prevalence of feline hyperthyroidism in Hong Kong and to determine the presence of potential risk factors associated with the disease in this specific geographic location.

\section{Materials and methods}

The study was conducted on cats that were presented at various veterinary practices in Hong Kong between June 2006 and August 2007. Cats were included in the study if they were 10 years of age or older and had spent their whole life in Hong Kong. Cats were excluded from the study if they were imported to Hong Kong from other countries, if they presented in shock or were moribund, if their physical state precluded the collection of a blood sample, if they were undergoing chemotherapy or if they had been treated with drugs that potentially affect $\mathrm{T}_{4}$ concentrations such as carbimazole, glucocorticoids and trimethoprim-potentiated sulphonamides. The veterinarians taking the samples completed a questionnaire regarding the health of each cat. Each owner completed a questionnaire regarding vaccination history, internal and external parasite control, diet and the environment of their cat.

Blood samples were collected by jugular venepuncture, transferred into plain tubes and centrifuged prior to separating the serum. The sera were stored at $-70^{\circ} \mathrm{C}$ and shipped on dry ice to the Veterinary Faculty at the University of Pretoria, South Africa where they were 
stored at $-80^{\circ} \mathrm{C}$. Serum total $\mathrm{T}_{4}$ concentration was determined by use of a commercially available radioimmunoassay (RIA) kit (Coat-A-Count canine total T, DPC, Los Angeles $\mathrm{CA})$. For total $\mathrm{T}_{4}$ the feline reference interval was $12.8-50.0 \mathrm{nmol} / 1(1.0-3.9 \mu \mathrm{g} / \mathrm{dl}){ }^{28}$ All cats with a serum total $\mathrm{T}_{4}$ concentration greater than $50 \mathrm{nmol} / 1$ were classified as hyperthyroid. Serum alanine aminotransferase (ALT) and alkaline phosphatase (ALP) activities were measured in all the samples by use of a modified colorimetric method (ALT) and a modified kinetic measurement (ALP), both from Alfa Wasserman clinical Chemistry systems (ACE \& NExCT).

Prevalence of hyperthyroidism, with exact binomial 95\% confidence intervals (CIs), was calculated for all cats combined, for cats classified as healthy (no clinically significant disease identified) and for those classified as sick. Prevalence was compared between healthy and sick cats using a two-tailed Fisher's exact test.

Univariable associations between potential risk factors and hyperthyroidism were assessed using a two-tailed Fisher's exact test. Thereafter, all predictors were entered into a multiple logistic regression model to estimate their effect on the risk of hyperthyroidism. To determine whether age should be included as a continuous or categorical variable, it was categorised into quintiles and the log odds of hyperthyroidism for each quintile was estimated using logistic regression. ${ }^{29}$ Because a monotonic change in estimated log odds was not seen with each successive quintile, age was modelled as a categorical variable with three categories (10-14 years, $15-19$ years and $\geq 20$ years). The model was developed by backward elimination by successively dropping the least significant predictor until all remaining independent variables were significant in the model with $P_{\text {Wald }} \leq 0.1$.

Associations between clinical signs and hyperthyroidism were assessed on a univariable level using a two-tailed Fisher's exact test. Associations between raised ALT activities and hyperthyroidism, and between raised ALP activities and hyperthyroidism, were assessed using a two-tailed Fisher's exact test.

The fit of the final logistic regression model for risk factors was assessed using the HosmerLemeshow goodness-of-fit test. All analyses were done using STATA version 10.0 (Stata Corporation, College Station, TX, USA).

\section{Results}

The study population consisted of 305 cats. Most of the cats were sampled at the Society for the Prevention of Cruelty to Animals (SPCA), Hong Kong clinics in Wanchai (250 cats), Kowloon (26 cats) and Hang Hau (seven cats). The remaining cats were sampled at private 
veterinary practices in Mid-Levels (17), Wanchai (three) and Happy Valley (two). Breeds included domestic shorthair (DSH) (181), domestic longhair (DLH) (61), Persian and Persian crosses (38), Angora (10), Himalayan (seven), Chinchilla (four), Siamese and Siamese crosses (three) and one British Shorthair. There were 166 females (153 ovariohysterectomised) and 139 males (120 castrated). The median age of the cats was 13 (range 10-26 years).

Of the 305 cats, 62 were presented for annual vaccinations, 57 were presented for routine visits and 184 were presented for various illnesses. Two cats were presented for unknown reasons. On the basis of the veterinary assessment the cats that were presented for routine visits were classified as 'healthy' or 'sick' and this brought the total of healthy cats to 95 and the total of the sick cats to 206 . The health status was not recorded for four cats.

Twelve cats were diagnosed as hyperthyroid (total $\mathrm{T}_{4}>50 \mathrm{nmol} / \mathrm{l}$ ). Their signalment and laboratory values are depicted in Table 1 . The prevalence of hyperthyroidism in the entire study population was 3.93\% (95\% CI: 2.05-6.77) and there was no significant difference in prevalence of hyperthyroidism between healthy $(3.16 \%)$ and sick $(4.37 \%)$ cats $(P=0.76)$ (Table 2).

Table 1.

Signalment and laboratory values of 12 hyperthyroid cats

\begin{tabular}{|l|l|l|l|l|l|l|}
\hline Cat number & Sex & Breed & Age & TT $_{4}(\mathbf{n m o l} / \mathbf{l})(\boldsymbol{\mu g} / \mathbf{d l})$ & ALT (U/l) & ALP (U/l) \\
\hline 3 & NF & DLH & 14 & $172.33(13.36)$ & 421 & 75 \\
\hline $21^{3}$ & NF & DLH & 17 & $53.36(4.14)$ & 195 & 45 \\
\hline 452 & NM & Chinchilla & 16 & $66.62(5.16)$ & 72 & 55 \\
\hline 620 & NF & DLH & 14 & $57.43(4.45)$ & 70 & 63 \\
\hline 628 & NM & Persian & 17 & $83.39(6.46)$ & 83 & 45 \\
\hline 745 & NF & DSH & 17 & $166.31(12.89)$ & 204 & 241 \\
\hline $752^{*}$ & NM & Persian & 19 & $104.21(8.08)$ & 69 & 56 \\
\hline $763 *$ & NF & DSH & 18 & $62.05(4.81)$ & 88 & 80 \\
\hline 774 & NF & DSH & 10 & $72.09(5.59)$ & 42 & 47 \\
\hline 784 & NF & DLH & 10 & $52.29(4.05)$ & 37 & 55 \\
\hline 812 & NF & DLH & 14 & $111.41(8.64)$ & 154 & 66 \\
\hline
\end{tabular}




\begin{tabular}{|l|l|l|l|l|l|l|}
\hline Cat number & Sex & Breed & Age & TT $_{\mathbf{4}}(\mathbf{n m o l} / \mathbf{l})(\boldsymbol{\mu g} / \mathbf{d l})^{\mathbf{1}}$ & ALT (U/l) $^{\mathbf{2}}$ & ALP (U/l) $^{\mathbf{3}}$ \\
\hline 835 & NF & DSH & 22 & $109.21(8.47)$ & 470 & 163 \\
\hline
\end{tabular}

$\mathrm{N}=$ neutered, $\mathrm{F}=$ female, $\mathrm{M}=$ male, $\mathrm{TT}_{4}=$ total $\mathrm{T}_{4}$.

Reference ranges: ${ }^{1}$ total $\mathrm{T}_{4} 12.8-50.0 \mathrm{nmol} / 1(1.0-3.9 \mu \mathrm{mol} / \mathrm{dl}) ;{ }^{2} \mathrm{ALT} 3.6-42 \mathrm{IU} / \mathrm{l} ;{ }^{3} \mathrm{ALP} 35-$ $123 \mathrm{IU} / 1$.

* These cats were considered healthy at the time of sampling.

Table 2.

Prevalence of hyperthyroidism (total $T_{4}>50 \mathrm{nmol} / \mathrm{l}$ ) in 305 cats 10 years and older presented to veterinary clinics in Hong Kong

\begin{tabular}{|l|l|l|l|}
\hline & Number of cats & Prevalence (\%) & $\mathbf{9 5 \%}$ CI \\
\hline Sick cats & $9 / 206$ & 4.37 & $2.02-8.13$ \\
\hline Healthy cats & $3 / 95$ & 3.16 & $0.66-8.95$ \\
\hline Disease status unknown & $0 / 4$ & 0.00 & $0.00-52.71$ \\
\hline Total & $12 / 305$ & 3.93 & $2.05-6.77$ \\
\hline
\end{tabular}

Although there were more female cats $(5.42 \%)$ with hyperthyroidism than male cats $(2.16 \%)$, the difference was not statistically significant (Table 3 ). There was no statistically significant relationship between vaccinations, parasite control or indoor environment and the development of hyperthyroidism. There was also no statistically significant relationship between the consumption of a canned food diet by the cats and hyperthyroidism.

Table 3.

Univariable analysis of risk factors for hyperthyroidism (total $T_{4}>50 \mathrm{nmol} / \mathrm{l}$ ) in cats 10 years and older presented to veterinary clinics in Hong Kong

\begin{tabular}{|l|l|l|l|l|l|}
\hline Variable & Category & $\boldsymbol{N}$ & \multicolumn{3}{|c|}{ Hyperthyroid cats } \\
\hline & & & $\boldsymbol{n}$ & $\%$ & $\mathbf{P}^{*}$ \\
\hline Age & $10-14$ years & 208 & 5 & 2.4 & 0.06 \\
\hline & $15-19$ years & 91 & 6 & 6.59 & \\
\hline
\end{tabular}




\begin{tabular}{|c|c|c|c|c|c|}
\hline \multirow[t]{2}{*}{ Variable } & \multirow[t]{2}{*}{ Category } & \multirow[t]{2}{*}{$N$} & \multicolumn{3}{|c|}{ Hyperthyroid cats } \\
\hline & & & $n$ & $\%$ & $P^{*}$ \\
\hline & 20-26 years & 6 & 1 & 16.67 & \\
\hline \multirow[t]{2}{*}{ Sex } & Female & 166 & 9 & 5.42 & 0.2 \\
\hline & Male & 139 & 3 & 2.16 & \\
\hline \multirow[t]{5}{*}{ Breed } & DSH & 181 & 4 & 2.21 & 0.2 \\
\hline & DLH & 61 & 5 & 8.2 & \\
\hline & Persian type & 49 & 3 & 6.12 & \\
\hline & Angora & 10 & 0 & 0 & \\
\hline & Other breed & 4 & 0 & 0 & \\
\hline \multirow[t]{3}{*}{ Number cats in house $\dagger$} & 1 & 161 & 5 & 3.11 & 0.9 \\
\hline & 2 & 60 & 2 & 3.33 & \\
\hline & $>2$ & 62 & 3 & 4.84 & \\
\hline \multirow[t]{2}{*}{ Vaccination $\dagger$} & Yes & 199 & 7 & 3.52 & $>0.999$ \\
\hline & No & 76 & 3 & 3.95 & \\
\hline \multirow[t]{2}{*}{ De-wormed $\dagger$} & Yes & 137 & 6 & 4.38 & 0.8 \\
\hline & No & 129 & 4 & 3.1 & \\
\hline \multirow[t]{2}{*}{ Flea control $\dagger$} & Yes & 138 & 7 & 5.07 & 0.3 \\
\hline & No & 124 & 3 & 2.42 & \\
\hline \multirow[t]{2}{*}{ Exclusively indoors $\uparrow$} & Yes & 258 & 9 & 3.49 & $>0.999$ \\
\hline & No & 20 & 0 & 0 & \\
\hline \multirow[t]{2}{*}{ Canned food diet $\dagger$} & Yes & 159 & 7 & 4.4 & $>0.999$ \\
\hline & No & 101 & 4 & 3.96 & \\
\hline \multirow[t]{2}{*}{ Water $\dagger$} & Tap unboiled & 119 & 5 & 4.2 & 0.6 \\
\hline & Tap boiled & 120 & 4 & 3.33 & \\
\hline
\end{tabular}




\begin{tabular}{|l|l|l|l|l|l|}
\hline Variable & Category & $\boldsymbol{N}$ & \multicolumn{3}{|c|}{ Hyperthyroid cats } \\
\hline & & & $\boldsymbol{n}$ & $\%$ & $\boldsymbol{P}^{*}$ \\
\hline & Other & 17 & 1 & 5.88 & \\
\hline
\end{tabular}

$N=$ number of cats from study population, $n=$ number of hyperthyroid cats.

${ }^{*} P$-value for two-tailed Fisher's exact test.

${ }^{\dagger}$ Data were not available for all of the cats in the study population.

Only breed and age were retained in the final logistic regression model of risk factors (Table 4). DSH cats tended to be less likely than all other breeds combined, to be diagnosed with hyperthyroidism (odds ratio $(\mathrm{OR})=0.30,95 \% \mathrm{CI}=0.08-1.06$ ), while there was a tendency for cats in the two older age categories to be more likely to be diagnosed with hyperthyroidism than 10-14 year old cats.

Table 4.

Final logistic regression model of risk factors for hyperthyroidism (total $T_{4}>50 \mathrm{nmol} / \mathrm{l}$ ) in cats 10 years and older presented to veterinary clinics in Hong Kong

\begin{tabular}{|l|l|l|l|l|}
\hline Variable & Category & OR & $\mathbf{9 5 \%}$ CI & $P$ \\
\hline Breed & DSH & 0.30 & $0.08-1.06$ & 0.06 \\
\hline & Other* & 1.00 & - & - \\
\hline Age & $10-14$ years* & 1.00 & - & - \\
\hline & $15-19$ years & 2.77 & $0.82-9.40$ & 0.10 \\
\hline & $20-26$ years & 11.88 & $1.06-133.7$ & 0.05 \\
\hline
\end{tabular}

Hosmer-Lemeshow goodness-of-fit test $\chi^{2}=0.38(3 \mathrm{df}), P=0.95$.

* Reference category.

Of the three hyperthyroid cats that were considered healthy, one presented for routine vaccination and two presented for routine health checks with no systemic signs. Of the nine hyperthyroid cats that were sick, three had gastrointestinal signs (vomiting and/or diarrhoea), two were seen because of weight loss, one was seen for an urocystolith and one was 
producing dilute urine and came in for a routine blood test. In two cats the illnesses were not specified. The mean $\pm \mathrm{SD} \mathrm{T}_{4}$ concentration in the three hyperthyroid cats classified as healthy was $73.2 \pm 27.2 \mathrm{nmol} / \mathrm{l}$, and that of the nine hyperthyroid cats classified as sick was $99.0 \pm 44.8 \mathrm{nmol} / 1$. This difference was not statistically significant $(P=0.38)$.

Table 5 lists the frequency of the main clinical features in the hyperthyroid cats. Weight loss and raised ALT activity were the most common findings, followed by vomiting, diarrhoea and polyphagia. Only one of the affected cats had a palpable thyroid lobe. Univariable analysis (Table 6) for these clinical signs as predictors of hyperthyroidism demonstrated that the presence of the following factors was significant $(P \leq 0.05)$ : polyphagia, diarrhoea and raised ALT and ALP activities.

Table 5.

Main clinical features in 12 hyperthyroid cats

\begin{tabular}{|l|l|l|}
\hline Finding & Number of cats & $\%$ \\
\hline Weight loss & 7 & 63.6 \\
\hline Alanine aminotransferase $>126(\mathrm{U} / 1)$ & 5 & 41.7 \\
\hline Vomiting & 4 & 36.4 \\
\hline Diarrhoea & 3 & 27.3 \\
\hline Polyphagia & 3 & 27.3 \\
\hline Tachycardia & 3 & 27.3 \\
\hline Alkaline phosphatase $>123(\mathrm{U} / \mathrm{l})$ & 2 & 16.7 \\
\hline Tachypnoea & 2 & 16.7 \\
\hline Cardiac murmur & 1 & 8.3 \\
\hline Palpable thyroid lobe & 1 & 8.3 \\
\hline
\end{tabular}

Table 6.

Univariable analysis of the clinical signs associated with hyperthyroidism (total $\left.T_{4}>50 \mathrm{nmol} / \mathrm{l}\right)$ in cats 10 years and older presented to veterinary clinics in Hong Kong*

\begin{tabular}{|l|l|l|l|l|l|}
\hline Variable & Category & $\boldsymbol{N}$ & \multicolumn{3}{|c|}{ Hyperthyroid cats } \\
\hline & & & $\boldsymbol{n}$ & $\%$ & $\boldsymbol{P} \uparrow$ \\
\hline Weight loss & Yes & 140 & 7 & 5.00 & 0.4 \\
\hline
\end{tabular}




\begin{tabular}{|c|c|c|c|c|c|}
\hline \multirow[t]{2}{*}{ Variable } & \multirow[t]{2}{*}{ Category } & \multirow[t]{2}{*}{$N$} & \multicolumn{3}{|c|}{ Hyperthyroid cats } \\
\hline & & & $n$ & $\%$ & $P \dagger$ \\
\hline & No & 155 & 4 & 2.58 & \\
\hline \multirow[t]{2}{*}{ Polyphagia } & Yes & 19 & 3 & 15.79 & 0.03 \\
\hline & No & 278 & 8 & 2.88 & \\
\hline \multirow[t]{3}{*}{ Heart rate } & $<200$ & 183 & 7 & 3.83 & 0.6 \\
\hline & $200-240$ & 93 & 4 & 4.30 & \\
\hline & $>240$ & 12 & 1 & 8.33 & \\
\hline \multirow[t]{2}{*}{ Cardiac murmur } & Yes & 39 & 1 & 2.56 & $>0.999$ \\
\hline & No & 260 & 11 & 4.23 & \\
\hline \multirow[t]{3}{*}{ Respiration } & Normal & 269 & 10 & 3.72 & 0.5 \\
\hline & Increased & 24 & 2 & 8.33 & \\
\hline & Dyspnoeic & 8 & 0 & 0.00 & \\
\hline \multirow[t]{2}{*}{ Vomiting } & Yes & 80 & 4 & 5.00 & 0.5 \\
\hline & No & 217 & 7 & 3.23 & \\
\hline \multirow[t]{2}{*}{ Diarrhoea } & Yes & 11 & 3 & 27.27 & 0.005 \\
\hline & No & 283 & 8 & 2.83 & \\
\hline \multirow[t]{2}{*}{ Palpable thyroid } & Yes & 2 & 1 & 50 & 0.08 \\
\hline & No & 296 & 11 & 3.72 & \\
\hline \multirow[t]{2}{*}{ Alanine aminotransferase $>126$} & Yes & 41 & 5 & 12.20 & 0.01 \\
\hline & No & 264 & 7 & 2.65 & \\
\hline \multirow[t]{2}{*}{ Alkaline phosphatase $>123$} & Yes & 6 & 2 & 33.33 & 0.02 \\
\hline & No & 298 & 10 & 3.36 & \\
\hline
\end{tabular}

* Data were not available for all of the cats in the study population.

${ }^{\dagger} P$-value for two-tailed Fisher's exact test. 


\section{Discussion}

The prevalence of hyperthyroidism in the study population of geriatric cats in Hong Kong was $3.93 \%$. This demonstrates that although this disease is present in Hong Kong the prevalence is lower than the reported prevalence in geriatric populations in Japan, the United Kingdom and Germany. ${ }^{16,18 \text { and } 21}$ The reason for the lower prevalence in Hong Kong could be due to differences in genetic factors, diet or environment and comparative epidemiological studies will be necessary to compare these factors between feline populations in Hong Kong and elsewhere.

There was no difference in the prevalence of hyperthyroidism between cats that were considered healthy and those that were considered sick. This highlights the fact that the disease is currently under-diagnosed in Hong Kong and that it is a challenging and insidious disease which, in its early stages, is often confused with other diseases or normal ageing changes.

Scarlett et $\mathrm{al}^{8}$ and Kass et $\mathrm{al}^{24}$ showed that Siamese cats have a significantly lower risk of developing hyperthyroidism compared with other breeds. In our study there were only three Siamese type cats and none of them had hyperthyroidism. However, when the DSH cats were compared with the rest of the cats, the shorthair group had a significantly lower likelihood of developing hyperthyroidism. It is, therefore, possible that there is a genetic protective factor involved in the DSH cats in Hong Kong. We suspect that a large percentage of the DSH cats in Hong Kong is of oriental (or Siamese) descent and this could explain the possible contribution of a genetic protective factor. None of the Angora cats in our study had hyperthyroidism, but the low number of Angora cats (10 cats) prevented any important conclusions.

In this study there was an increased risk of hyperthyroidism with increasing age, although the magnitude of this increase could not be estimated precisely due to the low number of cases. This is consistent with the findings of previous studies ${ }^{25}$ and also concurs that feline hyperthyroidism is a disease of middle-aged to old cats. There were more female than male cats that had hyperthyroidism but the difference was not statistically significant. Most of the previously published studies reported no sex predilection for feline hyperthyroidism., $3,7,10$ and 24 There were, however, two studies that showed a significant association between female cats and hyperthyroidism ${ }^{17}$ and 19 whereas in one study ${ }^{18}$ there were significantly more male than female cats affected. 
In the present study an association between feeding canned food and the development of hyperthyroidism was not found. This finding is in sharp contrast to previous studies where a strong association was found between feeding canned food and developing the disease. $8,17,19$, 24 and 25 Seven of the hyperthyroid cats in our study ate a mixed canned/dry food diet and four cats ate an exclusive dry food diet. (Dietary information was not provided for the remaining cat.) The lack of evidence for canned food being associated with feline hyperthyroidism can be due to the low numbers of hyperthyroid cats in our study, different packaging materials or even different iodine content of the canned food in Hong Kong. The presence of hyperthyroidism in cats that are fed exclusively dry food can be due to the presence of a different causative factor in either the food or the environment of these cats. However, hyperthyroidism may have a multi-factorial aetiology and there could potentially be an interaction with a genetic predilection.

There were no characteristic clinical features amongst the cats that were hyperthyroid and only one cat exhibited the typical clinical syndrome of voracious appetite with severe weight loss that has been described elsewhere. ${ }^{1,3,5,7,10 \text { and } 30}$ The lack of characteristic clinical signs could be due to the presence of a mild or early form of the disease, but could also be due to an atypical form of the disease. Despite the absence of recognisable clinical signs, this study showed that the disease needs to be considered if any of the following factors are present in an older cat: polyphagia, diarrhoea and raised ALT and ALP activities.

The present study had several limitations that need to be considered. The low prevalence of hyperthyroidism made it difficult to compare the group of hyperthyroid cases with the other cats. It is also possible that there could be some bias, because the study only included cats that were brought in to veterinary practices by their owners. However, the type of owner that brings their pet in for veterinary care is most likely the type of owner that could expose their cat unintentionally to the possible risk factors such as canned food, indoor environment and topical ectoparasite applications that have been described in previous studies. Another major limitation is the size of the study population - a bigger study population would have yielded more positive cats and might have produced more statistically significant results.

Another shortfall of this study was that hyperthyroid cats with early or subclinical disease or hyperthyroid cats with severe concurrent non-thyroidal illness would have been missed due to normal serum $\mathrm{T}_{4}$ concentrations. ${ }^{3,22,23 \text { and } 32}$ Peterson et $\mathrm{al}^{31}$ found that 80 of $917(8.7 \%)$ cats with hyperthyroidism had serum total $\mathrm{T}_{4}$ concentrations within reference range. If this figure is extrapolated to the current study the total prevalence could have been as high as $4.3 \%$. 
This study concluded that the prevalence of hyperthyroidism in cats in Hong Kong is less than in most other parts of the world, despite the presence of previously identified risk factors. It is possible that the prevalence of the disease will increase in future unless we can identify and eliminate known risk factors. The disease should be considered in any aged cat that presents with polyphagia, diarrhoea or raised ALT and ALP activities.

\section{Acknowledgements}

This study would not have been possible without the cooperation of veterinarians and cat owners in Hong Kong to whom the authors are greatly indebted. Our gratitude is extended to Ms Marianne Leung of Pathlab Medical Laboratories, Hong Kong who not only took care of the frozen samples but also provided valuable support in collecting as well as transporting of the samples. Financial support was provided by the Waltham Foundation, Waltham Centre for Pet Nutrition, Waltham-on-the-Wolds, United Kingdom.

\section{References}

1 M.E. Peterson, Feline hyperthyroidism, Vet Clin North Am Small Anim Pract 14 (1984), pp. $809-826$.

2 S.M. Meric, Diagnosis and management of feline hyperthyroidism, Compend Contin Educ Pract Vet 11 (1989), pp. 1053-1062.

3 K.L. Thoday and C.T. Mooney, Historical, clinical and laboratory features of 126 hyperthyroid cats, Vet Rec 131 (1992), pp. 257-264.

4 M.E. Peterson, J.F. Randolf and C.T. Mooney, Endocrine diseases. In: R.G. Sherding, Editor, The cat: diseases and clinical management (2nd edn.), Churchill Livingstone, New York (1994), pp. 1416-1452.

5 J. Holzworth, P. Theran, J.L. Carpenter, N.K. Harpster and R.J. Todoroff, Hyperthyroidism in the cat: ten cases, J Am Vet Med Assoc 176 (1980), pp. 345-353.

6 M. Hoenig, M.H. Goldschmidt, D.C. Ferguson, K. Koch and M. Eymontt, Toxic nodular goitre in the cat, J Small Anim Pract 23 (1982), pp. 1-12.

7 M.E. Peterson, P.P. Kintzer and P.G. Cavanagh et al., Feline hyperthyroidism: pretreatment clinical and laboratory evaluation of 131 cases, J Am Vet Med Assoc 183 (1983), pp. 103110.

8 J.M. Scarlett, N.S. Moise and J. Rayl, Feline hyperthyroidism: a descriptive and casecontrol study, Prev Vet Med 6 (1988), pp. 295-309. 
9 J.M. Scarlett, Epidemiology of thyroid diseases of dogs and cats, Vet Clin North Am Small Anim Pract 24 (1994), pp. 477-486.

10 J.D. Broussard, M.E. Peterson and P.R. Fox, Changes in clinical and laboratory findings in cats with hyperthyroidism from 1983 to 1993, J Am Vet Med Assoc 206 (1995), pp. 302-305. 11 D.S. Bruyette, Feline endocrinology update, Vet Clin North Am Small Anim Pract 31 (2001), pp. 1063-1081.

12 H. Gerber, H. Peter, D.C. Ferguson and M.E. Peterson, Etiopathology of feline toxic nodular goiter, Vet Clin North Am Small Anim Pract 24 (1994), pp. 541-565.

13 J.A. Taylor, R.M. Jacobs, J.H. Lumsden and B.N. Bonnett, Perspectives on the diagnosis of feline hyperthyroidism, Can Vet J 30 (1989), pp. 477-481.

14 M.F. Tarttelin, L.A. Johnson, R.R. Cooke, H.C. Ford and C.M. Feek, Serum free thyroxine levels respond inversely to changes in levels of dietary iodine in the domestic cat, N Z Vet J 40 (1992), pp. 66-68.

15 D.G. Bucknell, Feline hyperthyroidism: spectrum of clinical presentations and response to carbimazole therapy, Aust Vet $J 78$ (2000), pp. 462-465.

16 T. Miyamoto, I. Miyata and K. Kurobane et al., Prevalence of feline hyperthyroidism in Osaka and the Chugoku Region, J Jpn Vet Med Assoc 55 (2002), pp. 289-292.

17 J. Olczak, B.R. Jones, D.U. Pfeiffer, R.A. Squires and E.U. Morris, Multivariate analysis of risk factors for feline hyperthyroidism in New Zealand, N Z Vet J 53 (2004), pp. 53-58.

18 R. Sassnau, Epidemiological investigation on the prevalence of feline hyperthyroidism in an urban population in Germany, Tierarztl Prax Ausg K Klientiere Heimtiere 34 (2006), pp. $450-457$.

19 C.H. Edinboro, J.C. Scott-Moncrieff, E. Janovitz, H.L. Thacker and L.T. Glickman, Epidemiological study of relationships between consumption of commercial canned food and risk of hyperthyroidism in cats, $J$ Am Vet Med Assoc 224 (2004), pp. 879-886.

20 W. Kraft and F. Buchler, Hyperthyroidism: incidence in the cat, Tierarztl Prax Ausg K Klientiere Heimtiere 27 (1999), pp. 386-388.

21 J. Wakeling, C. Melian, A. Font, J. Elliott and H. Syme, Evidence for differing incidences of feline hyperthyroidism in London UK and Spain, Congress Proceedings 15th ECVIM-CA, Glasgow, Scotland, Poster 43 (2005), p. 220.

22 D.C. Ferguson, Pathogenesis of feline hyperthyroidism. In: J.J. August, Editor, Consultations in feline medicine, WB Saunders, Philadelphia (1994), pp. 136-137.

23 D. Gunn-Moore, Feline endocrinopathies, Vet Clin North Am Small Anim Pract 35 (2005), pp. $171-210$. 
24 P.H. Kass, M.E. Peterson, J. Levy, K. James, D.V. Becker and L.D. Cowgill, Evaluation of environmental, nutritional, and host factors in cats with hyperthyroidism, J Vet Intern Med 13 (1999), pp. 323-329.

25 K.M. Martin, M.A. Rossing, L.M. Ryland, R.F. DiGiacomo and W.A. Freitag, Evaluation of dietary and environmental risk factors for hyperthyroidism in cats, $\mathrm{J}$ Am Vet Med Assoc 217 (2000), pp. 853-856.

26 R.O. Mumma, K.A. Rashid and B.S. Shane et al., Toxic and protective constituents in pet foods, Am J Vet Res 47 (1986), pp. 1633-1637.

27 L.A. Johnson, H.C. Ford, M.F. Tarttelin and C.M. Feek, Iodine content of commercially prepared cat foods, $N Z$ Vet J 40 (1992), pp. 18-20.

28 R.J. Kemppainen and J.R. Birchfield, Measurement of total thyroxine concentration in serum from dogs and cats by use of various methods, Am J Vet Res 67 (2006), pp. 259-265. 29 I.H. Dohoo, S.W. Martin and H. Stryhn, Veterinary epidemiologic research, AVC Inc, Charlottetown (2003) 351.

30 S.R. Merchant and J. Taboada, Endocrinopathies thyroid and adrenal disorders, Vet Clin North Am Small Anim Pract 27 (1997), pp. 1285-1303.

31 M.E. Peterson, C. Melian and R. Nichols, Measurement of serum concentrations of free thyroxine, total thyroxine and total triiodothyronine in cats with hyperthyroidism and cats with non-thyroidal disease, J Am Vet Med Assoc 218 (2001), pp. 529-536.

32 M.E. Peterson and D.A. Gamble, Effect of non-thyroidal illness on serum thyroxine concentrations in cats: 494 cases, J Am Vet Med Assoc 1990 (197) (1988), pp. 1203-1208. 